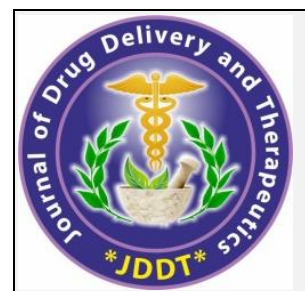

Available online on 02.01.2021 at http://jddtonline.info Journal of Drug Delivery and Therapeutics

Open Access to Pharmaceutical and Medical Research

(C) 2011-20, publisher and licensee JDDT, This is an Open Access article which permits unrestricted non-commercial use (CC By-NC), provided the original work is properly cited

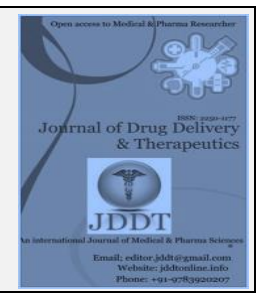

Open 1 Access

Case Report

\title{
Acute renal artery thrombosis associated with the use of an oral contraceptive pill
}

\author{
Kamel El-Reshaid *, Shaikha Al-Bader **, Zaneta Markova *** \\ *Department of Medicine, Faculty of Medicine, Kuwait University, Kuwait \\ ** Department of Medicine, Nephrology unit, Amiri hospital, Ministry of health, Kuwait \\ *** Departement of Radiology, IMC, Kuwait
}

\begin{abstract}
Peripheral, and even visceral, venous thromboembolism is a known complication of oral contraceptive drugs (OCPs) but arterial disease, leading to renal infarction, is rarely reported. We describe a 36-year-old female patient who presented with sudden left loin pain for 2 days. Ultrasound examination showed a wedge-shaped echogenic lesion at lateral side of the left kidney. Computed tomography with contrast showed the area to be avascular and the arteriogram showed abrupt loss of the dorsal branch of left main renal artery, which lacked any deformities, confirming diagnosis of thrombosis-in-situe. Moreover, the pelvicalyceal system did not show abnormality which ruled out ascending infection. The patient did not have a family history or laboratory evidence of hypercoagulable disorder. An OCP was the only medication she had received in the previous 3 months. The OCP was discontinued, and the patient was treated with heparin for 3 days then Abixaban for 6 months. Subsequent CT study with contrast, 3 months later, showed lateral kidney scar. On follow up; she did not have subsequent thrombotic events up to 1 year.
\end{abstract}

Keywords: Abixaban, infarction, Kidney, oral contraceptive, thrombosis.

Article Info: Received 06 Oct 2020; $\quad$ Review Completed 22 Nov 2020; $\quad$ Accepted 08 Dec 2020; Available online 02 Jan 2021

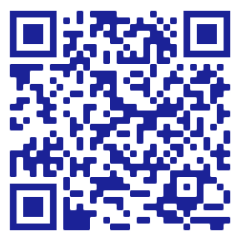

Kuwait

\section{Cite this article as:}

El-Reshaid K, Al-Bader S, Markova Z, Acute renal artery thrombosis associated with the use of an oral contraceptive pill, Journal of Drug Delivery and Therapeutics. 2020; 10(6-s):8-10 http://dx.doi.org/10.22270/jddt.v10i6-s.4494

*Address for Correspondence:

Dr. Kamel El-Reshaid, Professor, Dept. of Medicine, Faculty of Medicine, Kuwait University, P 0 Box 24923, 13110 Safat,

\section{INTRODUCTION}

Renal infarction is rare. In a study of 14,411 autopsies published in 1940, the incidence of renal infarction (RI) was 1.4 percent 1 . Moreover, in a series of almost 250,000 patients seen at an emergency department over four years, only 17 (0.007 percent) were diagnosed with acute renal infarction 2. The two major causes of renal infarction are thromboemboli and in situ thrombosis. Thromboemboli usually originate from a thrombus in the heart or aorta, and in situ thrombosis is usually due to an underlying hypercoagulable condition and injury to or dissection of a renal artery ${ }^{3}$. Although oral contraceptive drugs (OCPs) have been strongly associated with venous thrombosis, reports on its visceral arterial thrombosis were limited to doubling risk of cerebrovascular ischemic strokes and higher incidence of myocardial infarction in non-smokers $(3$ per million women over 1 year) 4 . To date, the association of OCPs with RI was reported in 2 cases 5, 6. Our present case report confirms such association and outlines its short and long-term management.

\section{THE CASE:}

A 36-year-old woman presented with sudden and severe left loin pain for the past 2 days. She did not have past medical history of significant medical illness, surgery, allergy or chronic intake of medications except for an OCP for 3 months. On her initial presentation; she had an isolated echogenic focus in the left kidney with hematuria and was managed as severe left pyelonephritis with broad-spectrum antibiotics and analgesics. She did not improve and hence was referred to us. She was afebrile and with normal blood pressure. Systemic examination did not show abnormality except for localized left loin tenderness. Laboratory investigations showed normal peripheral leucocyte and platelets counts. Hemoglobin was normal. Serum sugar, urea, creatinine, electrolytes, and liver functions were normal. Serum LDH was high at $1420 \mathrm{U} / \mathrm{L}$ (normal < 280). Urine routine and microscopy showed 25 red blood cells/high power field but no pyuria or proteinuria. Serum complements (C3 and C4) and protein electrophoresis were normal. Anti-neutrophil antibody, anti-neutrophil cytoplasmic antibody, and hepatitis B and C serology were 
negative. Abdominal and pelvic ultrasound revealed a wedge-shaped echogenic lesion in the left kidney expanding from medulla to its cortex. A contrast-computed tomography of the abdomen, revealed a non-enhancing wedge-shaped area in the left kidney (Fig. 1). Its initial arteriogram showed normal renal arteries and their branches except for an abrupt loss of the dorsal branch of left main renal artery confirming diagnosis of thrombosis-in-situe. Thrombophilia screening confirmed normal levels of PT and APTT, lupus anticoagulant, fibrinogen, factor VIII-c, functional protein $\mathrm{C}$ and $\mathrm{S}$ activity, anti-thrombin and activated protein $\mathrm{C}$ resistance, factor V Leiden, and prothrombin 20210A gene mutation. OC was discontinued and she was treated with heparin for 3 days followed by Warfarin for 6 months. On follow up; she did not have subsequent thrombotic events up to 1 year.

\section{DISCUSSION}

Acute flank pain associated with hematuria and high LDH should raise suspicion of renal artery infarction 7 Examination with a color duplex ultrasonography; usually reveals a characteristic wedge-shaped hypoechogenic renal lesion 8. Moreover, CT with contrast confirms the diagnosis especially with flip-flop enhancement sign ${ }^{9}$. CT angiography aids in diagnosis of local predisposition which is essential for management with balloon angioplasty for atheroembolic disease and immunosuppressive therapy in vasculitis 10 . If embolic disease is excluded by clinical assessment and echocardiography; in-situe thrombosis is the culprit. The latter dictates detailed search for hypercogaulable states and offending drugs. The list includes; OCP, Marijuana smoking, Cocaine, anabolic steroids, melanotan, NSAIDs, thrombophilic disorders and even Covid-19 infection 11-17. In those reports, enhancement of platelet aggregation, increased thromboxane synthesis and drug-induced endothelial and vasospastic injury were the most plausible mechanisms of infarctions. In females the use of OCPs is a risk factor and is much higher in patients with hypercoagulable states indicating its testing in each case 18. The most extensive study on the Risk of Arterial Thrombosis in Relation to Oral Contraceptives confirmed that the use of any type of OCPs (first, second or third generation) increases the risk of ischaemic stroke, MI and peripheral artery disease with an OR 1.7-2.4 19. RI is a serious disease and depending upon the severity, it can lead to acute renal failure in $39 \%$ of cases, renovascular hypertension in $48 \%$ and chronic kidney disease in $33.8 \% 20$. Hence, early diagnosis and intervention are essential in salvaging permanent kidney damage. In dogs, renal ischaemia for 2 hours was followed by gradual recovery of renal function over 2-3 weeks. Ischaemia for 4 hours caused irreversible renal damage 21 . Hence, the window period from the onset of symptoms to onset of irreversible renal injury was 3 hours 22 . However, in catheter-based thrombolysis, successful perfusion of renal arteries was reported up to 24 hours later 23 . If catheterbased or systemic thrombolyses are unavailable or risky; systemic anticoagulation is the last alternative. It was reported to be successful with enoxaparin started 5 hours in a similar OCPs-induced RI ${ }^{6}$. The latter may be used in patients with localized infarct and late presentation with an aim to avoid further spread of infarction. As in our case; a local scar was unavoidable. In conclusion; RI should be suspected in female patients with flank pain while receiving OCPs. Discontinuation of the drug, testing for underlying hypercoaulable state, and early intervention with systemic thrombolysis or anticoagulation may prevent life-threating complications.
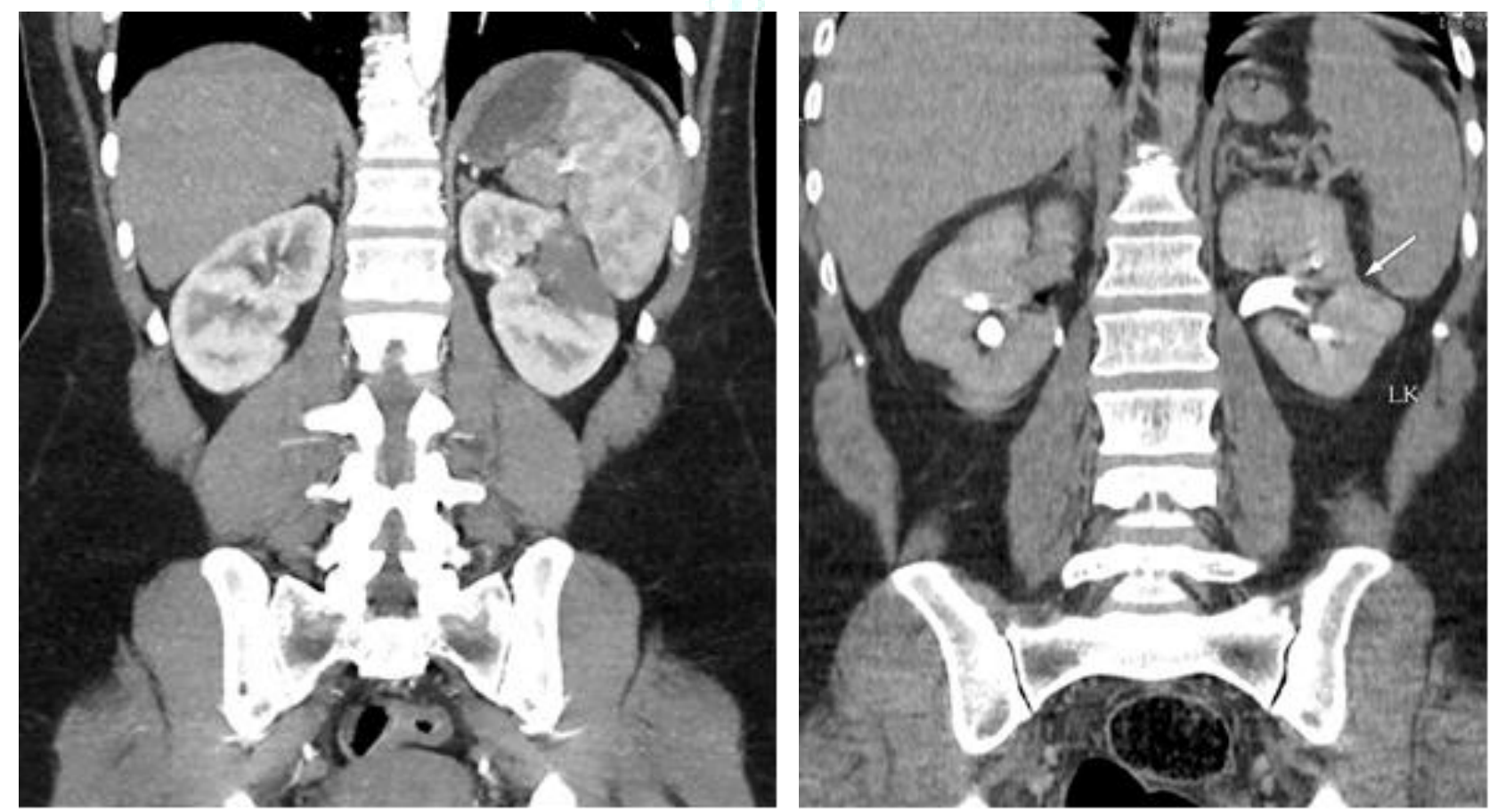

Figure 1: CT scan with contrast images of the abdomen at (A) initial presentation: showing a non-enhansing wedge-shaped area at anterolateral region of left kidney and (B) 3 months later: showing a wedge-shaped focal cortical defect corresponding to the area of infarction. The pelvicalyceal system does not show abnormality ruling out ascending infection. 


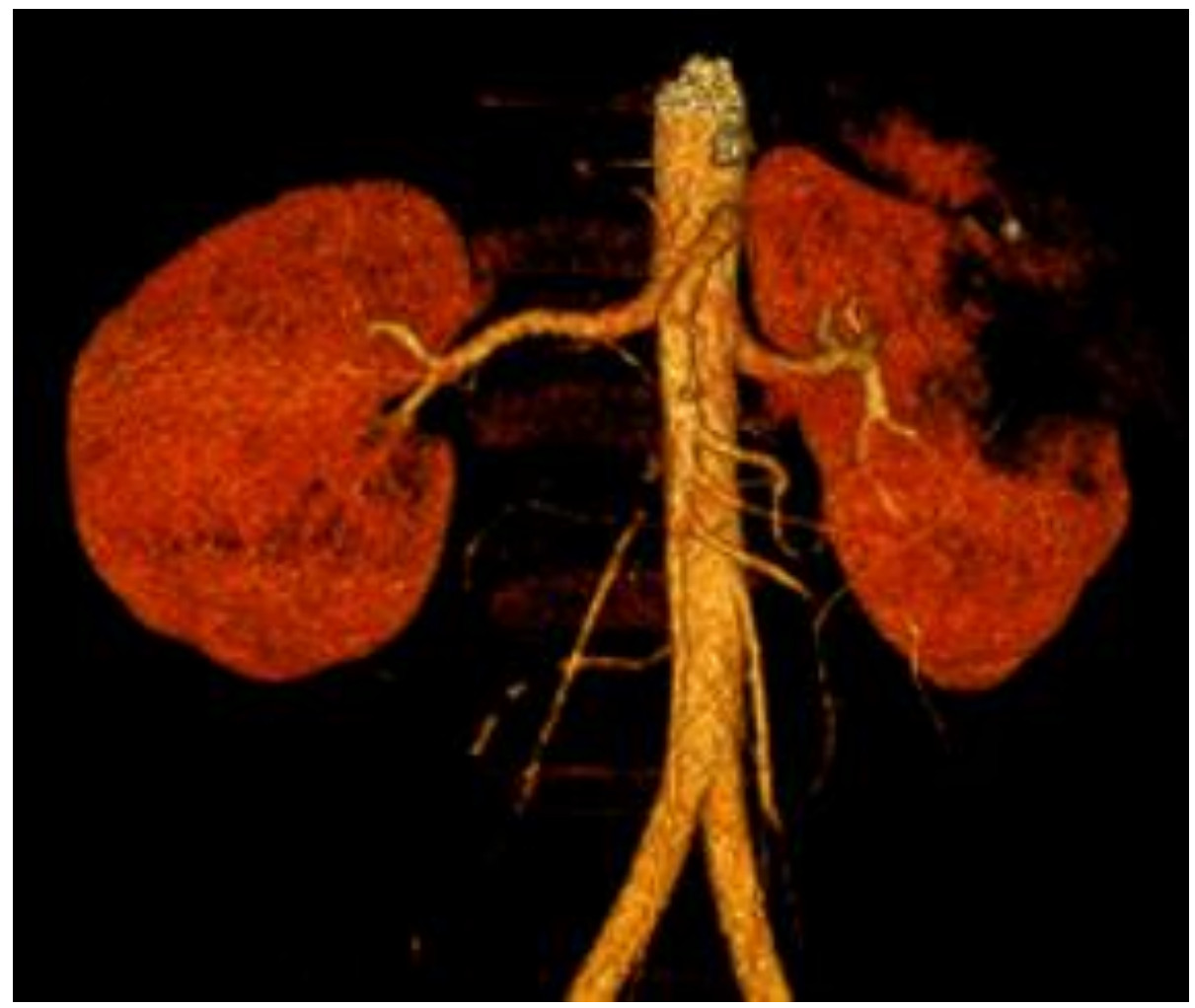

Figure 2: The initial arteriogram phase of the patient showing normal renal arteries and their branches except for an abrupt loss of the dorsal branch of left main renal artery.

\section{REFERENCES:}

1. Hoxie HJ, Coggin CB. Renal infarction: Statistical study of two hundred and five cases and detailed report of an unusual case. Arch Intern Med 1940; 65:587-594.

2. Paris B, Bobrie G, Rossignol P, Rossignol P, Le Coz S, et al. Blood pressure and renal outcome in patients with kidney infarction and hypertension. J Hypertens 2006; 24:1649-1654.

3. Antopolsky M, Simanovsky N, Stalnikowicz R, Salameh S, Hiller N. Renal infarction in the ED: 10-year experience and review of the literature. Am J Emerg Med 2012; 30:1055-1060.

4. Pymar HC, Creinin MD. The risks of oral contraceptive pills. Semin Reprod Med 2001; 19:305-312.

5. Guditi S, Ram R, Vasa R, Harke M, Prayaga A, et al. Renal infarction due to oral contraceptive pills. Clin Kidney J 2012; 5:283.

6. Bhargava A, Chopra A, Bernabela L, Chopra T. Oral contraceptive causing renal artery thrombosis. BMJ case reports 2013; bcr2012008055.

7. Domanovits H, Paulis M, Nikfardjam M, et al. Acute renal infarction. Clinical characteristics of 17 patients. Medicine 1999; 78:386-394.

8. Riehl J, Schmitt H, Bongartz D, Bergmann D, Sieberth HG. Renal artery stenosis. Evaluation with colour duplex ultrasonography. Nephrol Dial Transplant 1997; 12:1608-1614.

9. Leto C. Flip-flop enhancement in renal infarction. Abdominal radiol 2019; 44:1625-1626.

10. Lengele JP, Christophe JL, Persu A. Renal infarction management towards an etiological approach? J Hypertens 2018; 36:490-492.

11. Lambrecht GL, Malbrain ML, Coremans P, Vebist L, Verhaegen H. Acute renal infarction and heavy Marjuana smoking. Nephron 1995; 70:494-496.

12. Hoefsloot W, de Vries RA, Bruijnen R, Bosch FH. Renal infarction after cocaine abuse: A case report and review. Clin Nephrol. 2009; 72:234-236.

13. Colburn S, Childers WK, Chacon A, Swailes A, Ahmad FM, Sahi R. The cost of seeking an edge: Recurrent renal infarction in setting of recreational use of anabolic steroids. Ann Med Surg (London) 2017; 14:25-28

14. Peters B, Hadimeri H, Wahlberg R, Afghahi H. Melanotan II: a possible cause of renal infarction: review of the literature and case report. CEN Case Rep 2020; 9:159-161.

15. See-Hee Y, Yong-Lim K, Sun-Hee P, Chan-Duck K, Ji-Young C, Sung-Ro Y. Renal infarction after NSAID treatment. Korean J Med 2012; 82:618-622.

16. Fraile P, Garcia-Cosmes P, Lerma JL, et al. A 48 year old male with renal infarction and thrombophilia. Nefrologia 2008; 28:463-464.

17. Post A, den Deurwaarder E, BakkerS, de Haas R, van Meurs M, et al. Kidney infarction in patients with Covid-19. AJKD 2020; 76:431-435

18. Combined oral contraceptives, thrombophilia and the risk of venous thromboembolism: a systematic review and metaanalysis. van Vlijmen EF, Wiewel-Verschueren S, Monster TB, Meijer K. J Thromb Haemost 2016; 14:1393-1403.

19. Kemmeren JM, Tanis BC, van den Bosch MA, et al. Risk of Arterial Thrombosis in Relation to Oral Contraceptives (RATIO) study: oral contraceptives and the risk of ischemic stroke. Stroke 2002; 33:1202-1208.

20. Kwon JH, Oh BJ, Ha SO, Kim DY, Do HH. Renal complications in patients with renal infarctions: Prevalence and risk factors. Kidney Blood Press Res 2016; 41:865-872.

21. Hamilton PB, Phillips RA, Hiller A. Duration of renal ischemia required to produce uremia. Am J Physiol 1948; 152:517-522.

22. Blum U, Billmann P, Krause T, Gabelmann A, Keller E, Moser E, Langer M. Effect of local low-dose thrombolysis on clinical outcome in acute embolic renal artery occlusion. Radiology 1993; 189:549-54.

23. Piffaretti G, Riva F, Tozzi M, Lomazzi C, Rivolta N, Carrafiello G, Castelli P. Catheter-directed thrombolysis for acute renal artery thrombosis: report of 4 cases. Vasc Endovascular Surg 2008; 42:375-379. 